\title{
Editorial
}

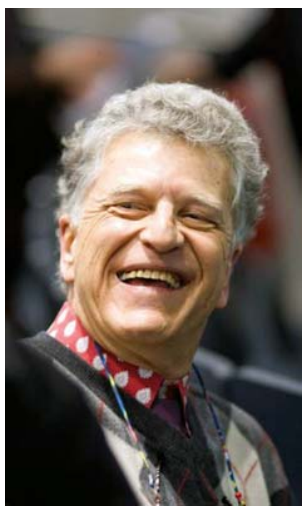

\section{Changing of the Guards}

\section{Dear Readers,}

September 1, 1989, marks the date at which the Inaugural Issue of SYNLETT appeared, a (somewhat battered) copy of which features prominently in my office (see below). Sometime earlier, the Thieme Publishing House had approached me with the proposal to take on the responsibility to start the journal as Editor in Chief. After considerable hesitation, I agreed, attracted by the challenge and the international flair of such a publication, and persuaded by the publisher's enthusiasm and promise of support. The latter included generous operating funds to enable the innovative use of telephone,

Fax, and FedEx

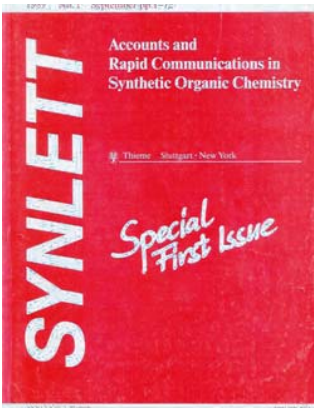

to accelerate the reviewing process (remember that computers came into general use years later!), a low subscription price, the establishment of a major award (now the Thieme-IUPAC Prize), and a commitment to support graduate students and postdoctorals in various ways.

An immediate and most pleasant task was to ask my friends and colleagues Bernd Giese, Steve Ley, and Hisashi Yamamoto to join me in this venture, and I was very pleased when they all agreed to do so (see right). The first issue contained Accounts by Hideki Sakurai on "Metamor- phosis of Synthetic Strategies with Allylic Silanes: Tetracoordinated Allylic Silanes into Pentacoordinated Allylic Silicates," and Jack Baldwin on "The Total Synthesis of ( \pm )-Isonitrin B (Deoxytrichoviridin)," followed by 29 Communications, led by one from my own group and including
K. Peter C. Vollhardt Department of Chemistry University of California
Berkeley, CA 94720, USA

Bernd Giese

Institute of Organic Chemistry St. Johanns Ring 19 CH-4056 Basel, Switzerland

Steven Victor Ley Department of Chemistry Imperial College of Science. London SW7 2 AY, United Kingdom

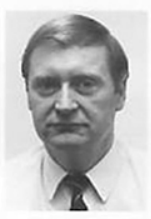

Hisashi Yamamoto Department of Applied Chemistry Faculty of Engineering Nagoya University Chikusa, Nagoya 464, Japan

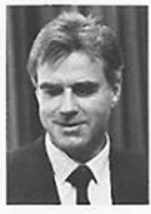

Born: 7 March 1946, Madrid, Spain.

Education: Vordiplom, University of Munich, 1967; Ph. D. University College, London (P. J. Garratt), 1972; Postdoc, California Institute of Technology (R. G. Bergman), 1972-1974. Profossional Exporionce: University of California, Berkeley, since 1974. Awards: Alfred P. Sloan Fellow, 1976-1980; Chevron Research Award, 1977; Camille and Henry Dreyfus Teacher-Scholar, 1978-1983; Senior Scientist Award, 1986; ACS Award in Organometallic Chemistry, 198

Research Interests: Mechanistic and Synthetic Exploratory Organic and Organometallic Chemistry; Transition Metals in Organic Synthesis, Novel Synthetic Methods, Non-Benzenoid Aromatics; Strained Rings; Transition Metal Clusters; Conductin

Born: 2 June 1940, Hamburg, FRG

Education: B. S., Universitics of Heidelberg and Hamburg; M.S University of Munich; Ph. D., University of Munich (R. Huisgen) Protity of Freiburg, 1976. dwigshafen, 1969-1971: 1978-1988; University of Basel, since 1989.
Awards: Kart-Winnaker Award, 1976; Carl-Duisberg Award, 1977; Gotffried-Wilhelm-Leibniz Award, 1986; Merck Award, 1988. Research Interests: Organic Chemistry; Synthesis with Radicals;
Carbohydrate Chemistry; Organometallic Chemistry.

Born: 10 December 1945, Stamford, Lincs., England, UK Education: B. Tech, Loughborough University. 1969; Ph. D. Loughborough University (H. Heaney), 1972; Postdoc, Ohio State (D. H. R B. A. Paquette), 1972-1974, Postdoc, Imperial college Chemistry), 1980; D. Sc. London University, 1983 Professional Experionce: Imperial College, since 1975. Awards: Royal Society of Chemistry, Hickinbottom Research Fellowship (1st Recipient). 1981-1983; Royal Society of Chemistry, 1980 Corday Morgan Medal and Prize, 1982; Pfizer Academic Award (Ist Recipient), 1983; Royal Society of Chemistry, Tilden Lectureship and Medal, 1988.

Research Interests: Organic Chemistry; Synthesis of Natural Chemistry; Organometallics in Synthesis; Modern Pesticides.

Born: 16 July 1943, Kobe, Japan

Education: B. S., Kyoto University (H. Nozaki), 1967; Ph. D. Harvard University (E. I Corey), 1971 Professional Experience: Toray Industries, Inc., 1971-1972; Kyoto University, 1972-1977; University of Hawaii, 1977-1980; Nagoya University, since 1980 Awards: Japanese Chemical Society Award for Young Chemist, 1977; Japan IBM Science Award, 1988

Research Interests: Organic Chemistry; Structure and Synthesis Complexes; Asymmeric Synthesis. Organetallic Chemistry and Metal 
many famous (or soon to be famous) authors, such as Scott Denmark, Ryoji Noyori, Hans-Ulrich Reissig, Ottorino De Lucchi, Ray Funk, Nico Speckamp, Bill Wulff, Phil Kocienski, Steve Davies, Shun-Ichi Murahashi, Bruce Lipshutz, and Bill Motherwell, among others.

As soon as the Inaugural Issue had been completed (the only issue in 1989), it became obvious that I needed some relief, as dealing with the intense promotion of SYNLETT
Today, 25 years later, SYNLETT is the prime international journal solely devoted to the dissemination of important results in synthetic organic chemistry. As it should be, the original group of editors has been replaced gradually by a new generation of individuals. Bernd Giese was succeeded by Ben List, Steve Ley by Laurence Harwood, Hisashi Yamamoto by Yas Uozumi, and Vic Snieckus by Tom Rovis. In addition, in 2008, we expanded the Board of Editors to include Hak-Fun Chow and Henry Wong, in charge of the Chinese Mainland, Taiwan, Hong Kong, and Macau. Thus, the journal is in good hands and in excellent shape. It is therefore with deep satisfaction that I am stepping down as Editor-in-Chief of SYNLETT and turning over the helm to Ben List, who has graciously accepted to steer the ship into the future. Rest assured, I am not retiring and will not disappear, but will restrict my activities to that of an Editor in charge of Accounts and Synpacts articles.

left me with precious little time for processing the Accounts and Communications sections. I was therefore very gratified when Vic Snieckus (see above) joined us in mid-1990 to take care of communications from the Americas. With the full initial team in place, we were off to the races.
With my best wishes for a successful, peaceful and happy New Year!

Peter Vollhardt

Berkeley, December 2014 


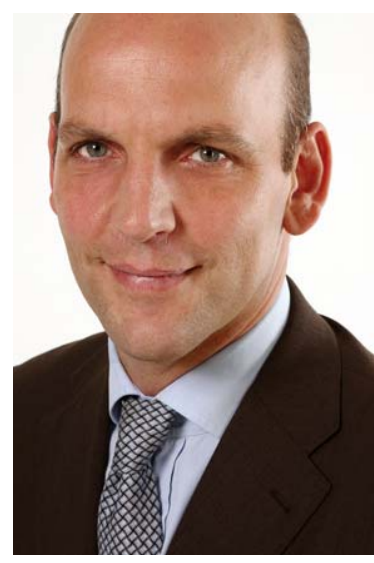

\section{Synlett $\mathbf{2 . 0}$}

Ever since I began reading the scientific literature, I particularly enjoyed the Thieme chemistry journals. Indeed, already as an undergraduate student in Berlin in the late 1980 s, I would spend some of my rather small allowance on a student subscription of SYNTHESIS. Back then, there was no internet, and I had to impatiently wait for the mail to deliver the latest issue. It was an easy read, with its clear style and detailed experimental procedures. So when SYNLETT appeared, I was immediately excited: not only did it publish stimulating communications on chemical synthesis, but it did so with the same great style and clarity, and with a certain flair that I couldn't find in other journals. As a graduate student, I was happy to publish one of my very first papers in SYNLETT. Then in 2000, after my first independent papers had appeared, Peter Vollhardt asked me to write an Account for SYNLETT. What an honor! Peter had developed a great journal with a personal flavor and a good sense for "hot" topics, especially those featuring young up-and-coming investigators. Being considered one of them made me happy and proud, and I immediately accepted. I was delighted by the result. Having been cited over 400 times, my 2001 Account on "Asymmetric Aminocatalysis" served for many of the following years as a guide to my scientific program. It not only led to more exciting papers, but also to my very first major research grant.

I very much look forward to assuming the position of Editor-in-Chief of SYNLETT in 2015. Succeeding Peter Vollhardt is a true honor for me. Together with his associate editors and the staff at Thieme, Peter has built a journal devoted to communications and accounts in chemical synthesis, the presence of which is a must in a good chemical library. I am committed to a continuation of the great tradition of publishing exciting synthetic chemistry with a young and personal touch. My coeditors and I will go out of our way to give you, the authors, the feeling of dealing with real people and scientists like yourself. We want to continue to provide a platform of success for young investigators proposing new and unusual ideas. They can do so in the form of the more established Communication and Account articles, as well as through our newer "Synpacts" forum, in which beginning investigators are given the opportunity to highlight a first breakthrough within the context of the broader literature. I am glad that Peter with his great experience and sense for originality has agreed to continue editing the Account and Synpacts sections. In addition, to attract the most interesting and urgent manuscripts, we want to make the journal one of the fastest in chemistry. We have already begun to label certain manuscripts as "Synfast" papers, which we can process from submission to online appearance within two weeks - without compromising quality reviewing! For hot science, speed matters. Finally, I also would like to bring special attention to younger and still growing areas such as organocatalysis or $\mathrm{C}-\mathrm{H}$ activation - and possibly to the exciting field that is just right now being developed in your own laboratory.

In 2015, SYNLETT will get a fresh start. It will be relaunched as the journal with a personal touch, with speedy publications, with a focus on young investigators and on emerging fields, with a new design, and hopefully, with great style. I will give my very best to help making SYNLETT one of the premiere places for synthetic chemists to publish their work. Finally, I would like to thank in advance all authors and referees, my associate editors, Peter Vollhardt, our colleagues and friends from Thieme, and our many readers for supporting us along the way.

Ben List

Mülheim, December 2014 